\title{
Mice depleted of the coxsackievirus and adenovirus receptor display normal spermatogenesis and an intact blood-testis barrier
}

\author{
Taranum Sultana ${ }^{1}, \mathrm{Mi} \mathrm{Hou}^{1, *}$, Jan-Bernd Stukenborg ${ }^{1, *}$, Virpi Töhönen ${ }^{2}$, Jose Inzunza ${ }^{2}$, \\ Andrei S Chagin ${ }^{1,3}$ and Kerstin Sollerbrant ${ }^{1}$ \\ ${ }^{1}$ Paediatric Endocrinology Unit, Department of Women's and Children's Health, ${ }^{2}$ Department of Biosciences \\ and Nutrition, Novum and ${ }^{3}$ Department of Physiology and Pharmacology, Karolinska Institutet, \\ Karolinska University Hospital, 17176 Stockholm, Sweden
}

Correspondence should be addressed to K Sollerbrant; Email: kerstin.sollerbrant@ki.se

*(M Hou and J-B Stukenborg contributed equally to this work)

\begin{abstract}
The coxsackievirus and adenovirus receptor (CXADR (CAR)) is a cell adhesion molecule expressed mainly in epithelial cells. Numerous evidence indicate that CXADR has an important role in testis development and function of the blood-testis barrier (BTB) in vitro. The role of CXADR in testis physiology in vivo has, however, not been addressed. We therefore constructed a conditional CXADR knockout (cKO) mouse model in which CXADR can be depleted at any chosen timepoint by the administration of tamoxifen. We report for the first time that testicular depletion of CXADR in adult and pubertal mice does not alter BTB permeability or germ cell migration across the BTB during spermatogenesis. Adult cKO mice display normal junctional ultra-structure and localization of the junctional proteins claudin-3, occludin, junction-associated molecule-A (JAM-A), and ZO1. The BTB was intact with no leakage of biotin and lanthanum tracers into the tubular lumen. Adult CXADR cKO mice were fertile with normal sperm parameters and litter size. Breeding experiments and genotyping of the pups demonstrated that CXADR-negative sperm could fertilize WT eggs. In addition, knocking down CXADR from postnatal day 9 (P9) does not affect testicular development and BTB formation. These cKO mice were analyzed at P49 and P90 and display an intact barrier and uncompromised fertility. We conclude that CXADR possesses no direct role in testicular physiology in vivo.

Reproduction (2014) 147 875-883
\end{abstract}

\section{Introduction}

The coxsackievirus and adenovirus receptor (CXADR $(C A R)$ ), first recognized as a receptor for coxsackievirus and adenovirus, is a junctional protein expressed in the epithelia of various tissues including testis (Raschperger et al. 2006). A number of expression studies and in vitro experiments have indicated an essential role of CXADR in the testes (Mirza et al. 2006, 2007, Wang \& Cheng 2007, Wang et al. 2007, Su et al. 2012). No in vivo studies addressing these findings have, however, been reported.

CXADR belongs to the cortical thymocyte marker of the Xenopus (CTX) family. In addition to CXADR, also the junction-associated molecules (JAM-A, JAM-B, and JAM-C) and junctional adhesion-like molecule (JAML) belong to this family (Chretien et al. 1998, Moog-Lutz et al. 2003). Some CTX family members play a critical role in transepithelial migration of circulating lymphocytes and leukocytes during inflammatory conditions, and some have also been suggested to facilitate transepithelial migration of male germ cells across the blood-testis barrier (BTB; Chavakis et al. 2004, Wang \& Cheng 2007, Verdino \& Wilson 2011). CTX proteins have also been reported to have other functions in the testis, such as regulation of sperm motility and spermatid differentiation (Gliki et al. 2004, Mirza et al. 2006, Sakaguchi et al. 2006, Shao et al. 2008).

In rodents, CXADR is highly expressed in both Sertoli and germ cells during perinatal and postnatal development up to the age of 17 days. On completion of BTB, at postnatal day 21 (P21) a sharp decrease in both mRNA expression and CXADR protein was observed (Mirza et al. 2007, Wang et al. 2007). In adult mice, CXADR expression becomes restricted and stage dependent and is predominantly localized to migrating preleptotene cells at stages VII and VIII enclosed in an intermediate compartment flanked by the tight junction marker occludin (Mirza et al. 2007). In addition, CXADR and claudin-3 were shown to localize to similar subcellular positions. Claudin-3 was previously reported to associate transiently with newly formed tight junctions 
at the time germ cells move across the BTB (Russell 1977, Mruk \& Cheng 2004, Mirza et al. 2007). These results suggested that CXADR might be involved in germ cell migration. Further support for this hypothesis was provided by the finding that Sertoli cells express JAML, a protein that was previously reported to form a functional complex with CXADR that supported transepithelial migration of leukocytes (Moog-Lutz et al. 2003, Zen et al. 2005). We therefore hypothesized that the CXADRJAML interaction facilitated migrating of preleptotene spermatocytes across the BTB via a similar mechanism.

On the basis of the presence of CXADR in the acrosome region of mature spermatozoa, CXADR has also been implicated to have a role in fertilization (Shaw et al. 2004, Mirza et al. 2006).

JAM-C, a protein absolutely required for proper differentiation of male germ cells, forms a complex with CXADR (Gliki et al. 2004, Mirza et al. 2006). In addition, CXADR partially co-localize with the junction markers ZO1, JAM-A and JAM-B as well as with occludin in the tubules that harbor migrating spermatocytes (Mirza et al. 2006, Wang \& Cheng 2007, Wang et al. 2007). These results suggest that CXADR is part of large protein complex localized at or near the BTB. Moreover, a recent in vitro study has revealed that CXADR disruption by siRNA resulted in mislocalized ZO1 and altered Sertoli cell barrier permeability (Su et al. 2012). These results point toward the role of CXADR in BTB maintenance.

The available in vivo knockout $(\mathrm{KO})$ models of various junctional proteins have helped to understand their physiological role in the testis, and they reveal varying phenotypes in mice. These include no apparent phenotype in JAM-B ${ }^{-1-}$ mice (Sakaguchi et al. 2006) and cingulin (Guillemot et al. 2004), slowly degenerative, as for occludin ${ }^{-1-}$ mice (Saitou et al. 2000), subfertility in JAM-A ${ }^{-1-}$ mice (Cooke et al. 2006), and sterility in claudin-11 ${ }^{-1-}$ and JAM-C ${ }^{-1-}$ mice (Gow et al. 1999, Gliki et al. 2004). The JAM-A ${ }^{-1-}$ phenotype was attributable to the role of JAM-A in the regulation of spermatozoal motility (Shao et al. 2008). No in vivo KO model has so far addressed the role of CXADR in the testis.

This study is the first in vivo model that explores the physiological role of CXADR in testis by using a conditional CXADR KO (CKO) mouse model. CXADRdepleted animals were generated by a tamoxifeninducible Cre system, in which the Cxadr gene could be excised at any chosen timepoint (Pazirandeh et al. 2011). We report a detailed characterization of testicular structure and function in the absence of CXADR.

\section{Materials and methods}

\section{Animal care and handling}

Mice were housed with unlimited access to food and water and exposure to $12 \mathrm{~h}$ light: $12 \mathrm{~h}$ darkness cycles and all animal experimentation was conducted in accordance with the accepted standards of humane animal care, and was approved by the Local Animal Ethical Committee at Karolinska Institutet, Stockholm (N179/08).

\section{CXADR cKO mice}

The CXADR cKO mice were generated using Cre/lox P technology published before (Pazirandeh et al. 2011), where the Cxadr gene can be disrupted in all tissues at any chosen timepoint by tamoxifen-regulated Cre-mediated recombination in vivo. Mice with a floxed Cxadr allele was generated at the MCI/ICS (Mouse Clinical Institute, Institut Clinique de la Souris, Illkirch, France). Briefly, mice were generated on a C57BL6 (+/+) background

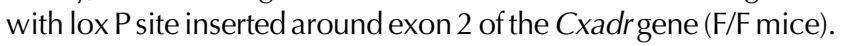
Further breeding with C57BL/6 mice expressing a universal CMVdriven tamoxifen-inducible Cre-Ertm gene $(+/+$;Cre mice) created mice harboring both the floxed Cxadr gene and the inducible CRE protein (F/F;Cre mice). Tamoxifen treatment activates CRE that results in the excision of the Cxadr gene and consequently a depletion of the CXADR protein. Littermates with genotypes $\mathrm{F} / \mathrm{F}$ or $+/+$; Cre were used as a control for the cKO animals as indicated in the text.

Genotyping was carried out by PCR on genomic DNA from tail using primer pairs described previously (Pazirandeh et al. 2011). In the PCR that uses a primer pair that encompasses one of the lox $P$ sites, the DNA fragment of 211 bp represents the WT allele, whereas the $261 \mathrm{bp}$ fragment represents the lox P-flanked allele. In DNA from cKO animals, in which the two lox $P$ sites have recombined, this PCR does not give rise to any PCR product.

\section{Tamoxifen gavage for the generation of adult and prepubertal CXADR CKO}

Adult animals (minimal age 4-6 weeks) of genotype F/F; Cre and F/F were gavaged with $0.25 \mathrm{mg} / \mathrm{g}$ body weight tamoxifen (Sigma, T5648) once a day for 5 consecutive days according to reported procedure (Young et al. 2008). Mice were killed and analyzed 3 weeks ('standard protocol', Pazirandeh et al. (2011)), 6 weeks, or 12 weeks following the first dose of tamoxifen. For fertility analysis, the male CXADR cKO mice and their control littermates were kept for 6 weeks following the first dose of tamoxifen in order to flush out all CXADR positive sperm before they were mated with WT females. For generation of prepubertal cKO, the pups received at $\mathrm{P} 8$ a single dose of $0.5 \mathrm{mg}$ tamoxifen as reported previously (Young et al. 2008). These mice were killed at P9, P24, P49, and P90. The efficiency of Cre-mediated excision was analyzed by PCR on genomic DNA isolated from the tail as described previously (Pazirandeh et al. 2011), and CXADR protein downregulation was examined by western blotting.

\section{Histological and transmission electron microscopic analysis}

For histological analysis, testes were fixed either in Bouin's solution for at least $16 \mathrm{~h}$ and stored in $70 \%$ ethanol at $4{ }^{\circ} \mathrm{C}$, or in $4 \%$ paraformaldehyde-PBS ( $\mathrm{pH} 7.2$ ) overnight and dehydrated in a graded series of ethanol. The samples were paraffin embedded and $5 \mu \mathrm{m}$-thick sections were stained with the 
periodic acid-Schiff-hematoxylin technique (PAS) and hematoxylin staining using standard protocols.

For transmission electron microscopy (TEM) analysis, the testes were immediately processed in $2 \%$ glutaraldehyde+ $0.5 \%$ paraformaldehyde in $0.1 \mathrm{M}$ sodiumcacodylate buffer containing $0.1 \mathrm{M}$ sucrose and $3 \mathrm{mM} \mathrm{CaCl}_{2}, \mathrm{pH} 7.4$ according to the published procedure (Pazirandeh et al. 2011). Semi-thin sections $(0.5 \mu \mathrm{m})$ were stained with toluidine blue and used for light microscopic analysis. Ultrathin sections ( 40-50 nm) were contrasted with uranyl acetate (Merck) and examined under a Leo 906 TEM at $80 \mathrm{kV}$ (Carl Zeiss SMT, Oberkochen, Germany). Digital images were taken by using a Morada digital camera (Soft Imaging System GmbH, Münster, Germany).

\section{Indirect double immunofluorescence and western blot analysis}

The method of protein extract preparation for western blot, tissue storage, and fixation for immunofluorescence was as reported previously (Sollerbrant et al. 2003, Mirza et al. 2006, 2007). A Leica confocal fluorescence microscope (Leica Microsystems GmbH, Wetzlar, Germany) was used for immunofluorescence analyses.

\section{Antibodies}

Rabbit, polyclonal anti-CXADR antibodies (IG1, RP1284, and RP291) and the antibody toward Calnexin have been described (Andersson \& Pettersson 1998, Raschperger et al. 2006). MAB toward rat occludin (MOC37) was a kind gift from Dr M Furuse, Kobe University, Japan. Rat anti-ZO1 is a MAB purchased from Chemicon, Billerica, MA, USA (MAB1520). Rabbit anti-occludin (ABT146), rabbit anti-ZO1 (AB2272), and rabbit anti-claudin-3 (ABT43) were from Zymed/Invitrogen (Life Technologies). Goat anti-JAM-A was from R\&D system (AF1077, Minneapolis, MN, USA). The antibodies were used in concentrations reported previously (Mirza et al. 2006, 2007). Secondary antibodies were goat anti-rabbit Alexa Fluor 488, donkey anti-rat Alexa Fluor 594 (A-11008 and A-21209, Molecular Probes, Burlington, ON, USA), and HRP labeled anti-rabbit IgG (RPN4301, GE Healthcare, Stockholm, Sweden, UK). Antibodies to acrosome marker PNA labeled with Alexa Fluor 488 (L21409) and secondary antibodies such as goat anti-rabbit Alexa-Fluor 546 antiserum (A11035) and Alexa-Fluor-488 Streptavidin (S32354) were purchased from Molecular Probes.

\section{Qualitative assessment of BTB permeability}

\section{Lanthanum immersion fixation and}

electron microscopic evaluation

Lanthanum immersion method was used for functional investigation of the BTB in adult CXADR cKO. Testes tissues were prepared according to reported method (Neaves 1973, Willems et al. 2010). Briefly, adult CXADR cKO (F/F;Cre mice) and littermate controls (F/F) were killed 3 weeks after the first tamoxifen treatment and the testes tissues were immediately pre-fixed for $5 \mathrm{~min}$ in the fixative containing 1\% lanthanum and $2 \%$ glutaraldehyde in $0.1 \mathrm{M}$ sodium cacodylate buffer at $\mathrm{pH} 7.3$ to allow it to harden the tissue. After that, testis were cut into small pieces $\left(2-3 \mathrm{~mm}^{2}\right)$ and immersed in the same fixative, for $5 \mathrm{~h}$, at room temperature. After immersion, tissue samples were rinsed in the same buffered lanthanum solution but without glutaraldehyde at $4{ }^{\circ} \mathrm{C}$ until processed. The tissues were then post fixed for $8 \mathrm{~h}$ in $1 \% \mathrm{O}_{\mathrm{s}} \mathrm{O}_{4}$ in $0.1 \mathrm{M}$ containing $1 \%$ of the same lanthanum solution at $\mathrm{pH} 7.2$ at $4{ }^{\circ} \mathrm{C}$. After overnight staining in $0.5 \%$ aqueous uranyl acetate, the samples were dehydrated in alcohol and embedded in Epon 812-Araldite. Ultrathin section $(\sim 40-50 \mathrm{~nm})$ were cut and contrasted with uranyl acetate (Merck) and examined in a Leo 906 TEM at $80 \mathrm{kV}$.

\section{Biotin tracer studies}

The integrity of BTB was analyzed in both adult CXADR cKO mice and sexually mature mice $\mathrm{KO}$ at P9 by intra-testicular infusion of biotin tracer according to reported methods (Meng et al. 2005). Briefly, adult mice from both treatment groups were anesthetized with pentobarbitone (Ayrton Saunders Ltd, Liverpool, UK) diluted $1: 10$ in $0.9 \% \mathrm{NaCl}$. The animals received $0.1 \mathrm{ml}$ of the diluted stock/10 g body weight by i.p. injections. Testes were injected with either the qualitative tight junction (TJ) functional tracer biotin $(10 \mathrm{mg} / \mathrm{ml}$, EZ-Link Sulfo-NHS-LC-Biotin; Pierce, Rockford, IL, USA) in a volume of $10 \%$ testis weight, or the biotin vehicle, $\mathrm{PBS}(\mathrm{pH} 7.4)$, and $1 \mathrm{mMCaCl}_{2}$. Testes were removed and directly fixed in optimum cutting temperature (OCT) and frozen after $30 \mathrm{~min}$. The penetration of the biotin tracer in tissue cryosections was visualized directly under fluorescence microscopy using Alexa-488 streptavidin (Molecular Probes). For co-localization studies with occludin, the sections were incubated with rabbit anti-occludin antibodies $(1: 200)$ for $1 \mathrm{~h}$, washed, and incubated with Streptavidin Alexa Flour along with the goat anti-rabbit Alexa-546 secondary antiserum (Molecular Probes).

\section{Sperm collection and sperm parameter analysis}

The sperm parameters were carried out as reported previously (Bjorndahl et al. 2002). Briefly, for motility analysis, the minced caudal epididymis was suspended in pre-warmed $\left(37^{\circ} \mathrm{C}\right) \mathrm{sperm}$ preparation medium (SU-medium) constituting Earle's balanced salt solution (E 2888; Gibco; Life Technologies), supplemented with sodium pyruvate (P4562; Gibco; Life Technologies), $1.1 \mathrm{mg} /$ ml; Penicillin-G (P 4687; Gibco; Life Technologies), 10000 IE/ml, and 1\% BSA (A8918; Gibco; Life Technologies). Duplicate samples of $5 \mu$ leach were used to estimate the number of motile, live immotile, and dead immotile sperms. For sperm count, $50 \mu \mathrm{l}$ of the above sperm suspension was diluted with $950 \mu \mathrm{l} 0.4 \%$ formalin (in distilled water containing $5 \% \mathrm{NaHCO}_{3}$ ). Each of the two chambers in an improved Neubauer chamber was filled, and after sedimentation, spermatozoa were counted according to NAFA ESHRE manual for semen analyses (World Health Organization 2010). The morphology was analyzed by examining sperm under light microscopy and also by staining with papanicolau stain. Three age-matched cKO and three littermate controls were used, and both sperm counts and sperm motility procedures were carried out twice for each sample and then averaged.

\section{Fertility assay}

Adult CXADR cKO male mice and control littermates at the age of 6 weeks were treated with tamoxifen as described earlier. 
They were then mated with 6-week-old WT C57BL6 females. Each mating pair was monitored over a 3-month period to examine the number of litters and the number of pups per litter. Prepubertal mice treated with tamoxifen at P9 were analyzed in the same way and control littermates at the age of 8 weeks. Western blot analysis was carried out at the completion of the fertility experiment to analyze CXADR expression in the testis.

\section{Statistical analysis}

Student's $t$-test with 'Shapiro-Wilk' normality test was used to compare averages between two different experimental groups (SigmaPlot 11.0; Systat Software, Inc., Erkrath, Germany). Number of pups per litter is expressed as mean \pm s.D. $P$ value of $\leq 0.05$ was considered statistically significant.

\section{Results \\ $C X A D R$ is efficiently downregulated in the testes of adult cKO mice}

We previously reported that tamoxifen-induced Cre-mediated deletion of the Cxadr gene in adult mice results in an efficient downregulation of the CXADR protein in several tissues (Pazirandeh et al. 2011). In this study, we extend this finding to include also the male reproductive system. Western blot analysis of whole testes extract from tamoxifen-treated adult mice demonstrated a significant decrease in CXADR protein levels in the testes of $\mathrm{CKO}$ animals compared with littermate controls (Fig. 1A). Calnexin was used as a loading control. Indirect immunostaining using a CXADRspecific antibody confirmed this result because the stage-dependent CXADR staining we reported previously was absent in the cKO mice (Mirza et al. 2007; Fig. 1B). CXADR remained downregulated for at least 3 months (length of experiment, Pazirandeh et al. (2011) and data not shown). CXADR was also efficiently downregulated in the vas deferens, seminal vesicles, and epididymis of tamoxifen-treated cKO animals (data not shown). CXADR was not expressed in Leydig cells in neither cKO animals nor controls (Fig. 1B).

We previously reported CXADR expression in male germ cells (Mirza et al. 2006). To analyze whether CXADR was downregulated in the mature sperm of $\mathrm{CKO}$ males, western blots were carried out on epididymal sperm extracts. The results demonstrate that the amount of CXADR protein detected in the sperm from cKO males is significantly lower compared with the littermate controls (Fig. 1C). Similarly, immunofluorescence analysis of isolated sperm revealed that $90 \%$ of the sperm cells lacked any detectable CXADR protein (Fig. 1D and data not shown). The remaining 10\% displayed faint CXADR staining which was not surprising considering the fact that tamoxifen-dependent, Cremediated, excision is normally not taking place in $100 \%$ of the target cells (Hayashi \& McMahon 2002).
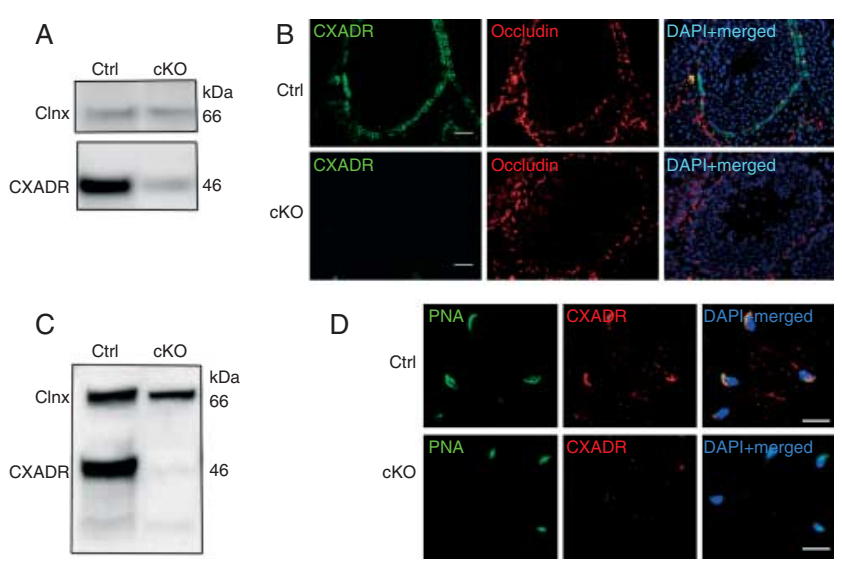

Figure 1 Downregulation of CXADR in adult testis following tamoxifen administration. (A and C) Western blot analyses of extracts from testis (A) and sperm $(\mathrm{C})$ isolated from tamoxifen-treated cKO mice (F/F;Cre) and littermate controls (Ctrl) (F/F). Calnexin (Clnx) was used as a loading control. $50 \mu \mathrm{g}$ protein was loaded in each lane. (B) Indirect immunofluorescence staining of testicular cross-sections using a CXADR-specific antibody (RP291) showing that CXADR was efficiently and specifically downregulated in tamoxifen-treated adult CXADR CKO mice at P90 in stage VIII tubules. Owing to the different fixation methods required to visualize CXADR in the epithelium and in the spermatids, CXADR staining is not very prominent in the spermatids in the control panel in this figure. An antibody toward occludin was included to visualize the BTB, and DAPI was included to facilitate identification of germ cells. (D) Indirect immunofluorescence staining of sperm from P140 tamoxifen-treated cKO (F/F;Cre) and littermate controls (Ctrl) (F/F). A fluorescence-labeled lectin (PNA) and DAPI were used to visualize the acrosome region and nucleus respectively. The results shown are representative of three independent experiments. Scale bar: $40 \mu \mathrm{m}$.

CXADR protein levels in tamoxifen-treated $+/+$; Cre control animals were indistinguishable from WT animals (Pazirandeh et al. (2011) and data not shown). Together these results demonstrated that Cre-mediated excision of the Cxadr gene was efficient in the testis, and that neither tamoxifen treatment itself nor the presence of the CRE protein alone can disrupt expression from the Cxadrgene.

\section{CXADR-depleted testis display normal morphology and sperm parameter}

Testicular size and weight were normal in adult cKO mice analyzed between 4 weeks and 4 months after the administration of tamoxifen (data not shown).

Histological analysis of PAS-stained testis sections from $\mathrm{CKO}$ animals showed normal tubular lumen size and presence of all differentiated stages of germ cells (Fig. 2A). Also the cellular organization in the seminiferous tubules, given by the Sertoli and germ cells, and the numbers and appearance of the interstitial cells of cKO animals appeared normal (Fig. 2A). Analysis by highresolution light microscopy of PAS-stained epididymal spermatozoa displayed morphologically normal cells with evenly stained acrosome regions and tails, indistinguishable from the littermate controls (Fig. 2B). In addition, the analysis of sperm from cKO mice at P140 


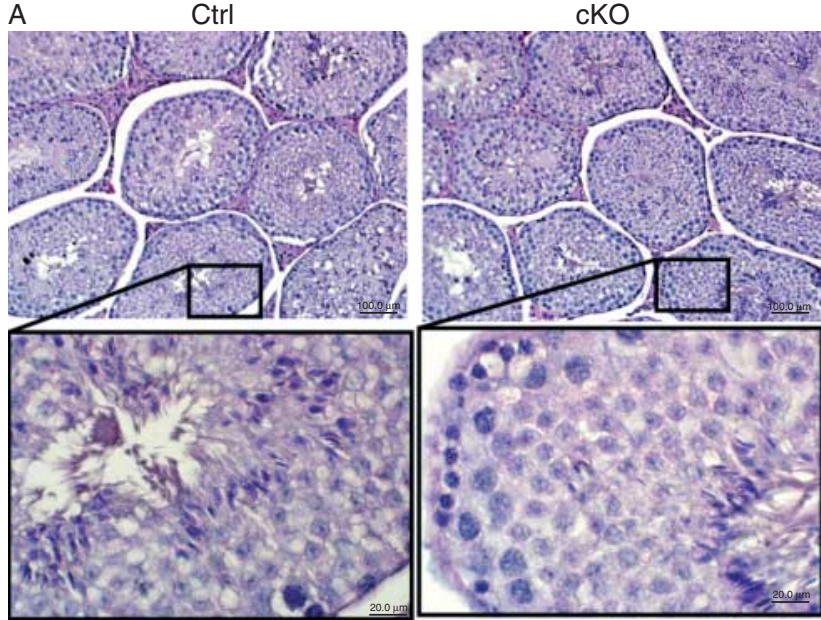

B
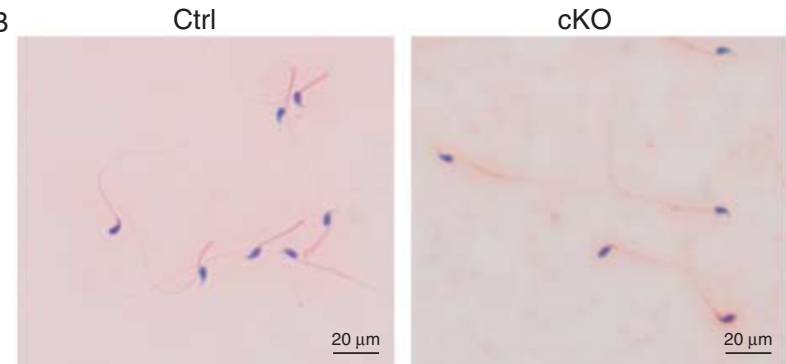

Figure 2 Gross morphology of testis and sperm was normal in adult tamoxifen-treated cKO animals. (A) PAS staining of testicular sections from mice at P50 control (Ctrl) (F/F) and CXADR cKO mice (F/F;Cre) showed apparently normal tubules with sperm in various stages of development. Images represent $20 \times$ and $100 \times$ resolution. Scale bars: 100 and $20 \mu \mathrm{m}$. (B) Sperm morphology was analyzed after papanicolau staining. Scale bars: $20 \mu \mathrm{m}$ (B). The results shown are representative of three independent experiments.

showed normal sperm titers $\left(1.98 \pm 0.09 \times 10^{6} / \mathrm{ml}\right)$ and motility $(60.3 \pm 3.78)$ when compared with littermate controls which had an average sperm count of $3.14 \pm$ $0.31 \times 10^{6} / \mathrm{ml}$ and motility $56.3 \pm 1.11$. The cKO sperm titer and motility were not significantly different from the littermate controls with $P$ values of 0.1 and 0.4 respectively $(P>0.05)$. Each value corresponds to the average of three age-matched males.

In addition, also the morphology of the vas deferens, seminal vesicles, and epididymis appeared normal (data not shown).

\section{Adult cKO mice have structurally normal cellular junctions at the $B T B$}

A detailed electron microscopic analysis of tight junctions and ectoplasmic specializations in the testes revealed no major differences in the Sertoli-Sertoli and Sertoli-germ cells junctions, respectively, between control and cKO mice (Fig. 3A). In addition, the subcellular distribution of the junctional proteins ZO1 occludin, JAM-A, and claudin3 appeared normal in testicular sections from adult cKO when analyzed by indirect immunofluorescence (Fig. 3B).
The same results were obtained when mice were analyzed up to the age of 8 months (length of experiment and data not shown). We conclude that the structure and protein composition of the cellular junctions at the BTB is unaffected in the absence of CXADR.

\section{Absence of CXADR does not affect the BTB integrity and function}

The integrity of BTB was analyzed in the adult cKO mice at P49 and P90 by immersion fixation of the freshly
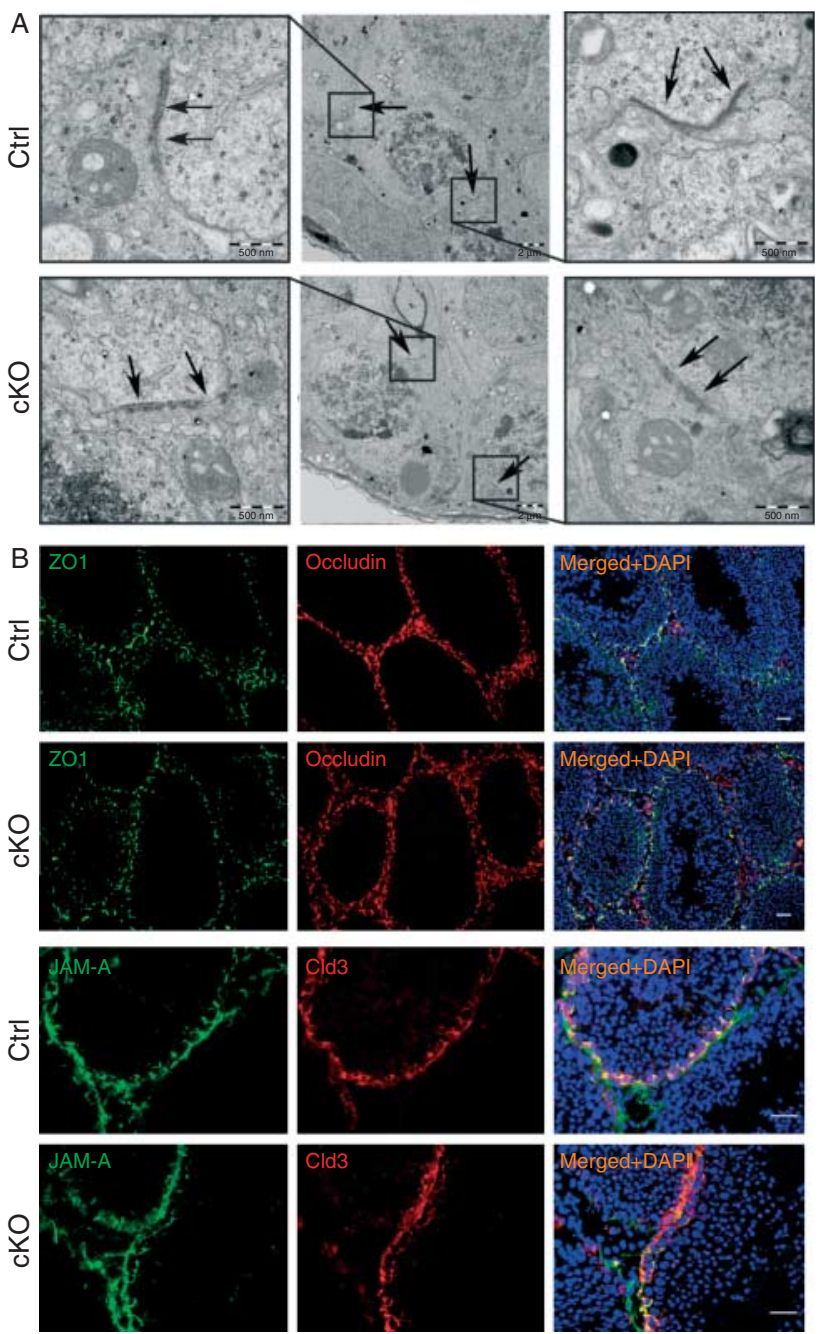

Figure 3 The structure of cellular junctions in CXADR-depleted adult mice is maintained. (A) Transmission electron microscopy (TEM) images of testes from P78 tamoxifen-treated cKO mice (F/F;Cre) and littermate controls (Ctrl) (F/F). No significant difference is seen at the Sertoli-Sertoli cell and Sertoli-Germ cell interfaces (arrow). High-resolution images are shown on the left and right side of the overview pictures. Scale bars: $2 \mu \mathrm{m}$ and $500 \mathrm{~nm}$. (B) Indirect immunofluorescence staining on frozen testicular sections derived from tamoxifen-treated cKO mice (F/F;Cre) and littermate controls (Ctrl) (F/F). Specific antibodies toward ZO1, occludin, JAM-A, and claudin-3 (Cld 3) were used. DAPI was included to visualize nuclei. Scale bar: $40 \mu \mathrm{m}$. The results shown are representative of three independent experiments. 
A

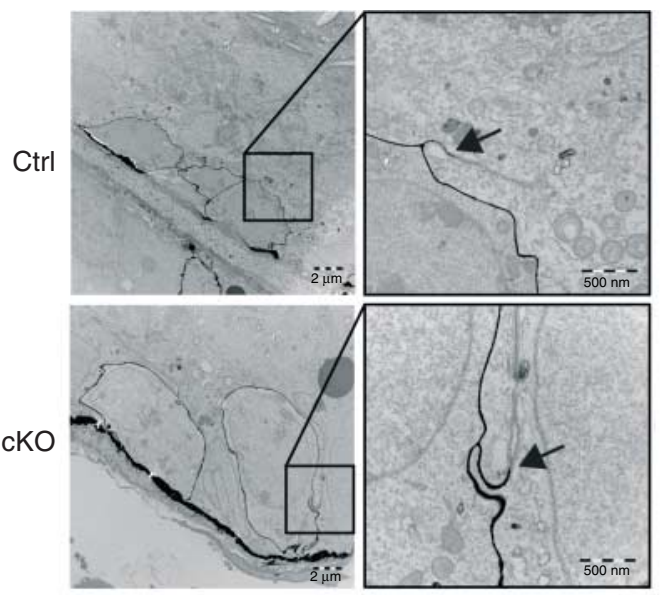

B
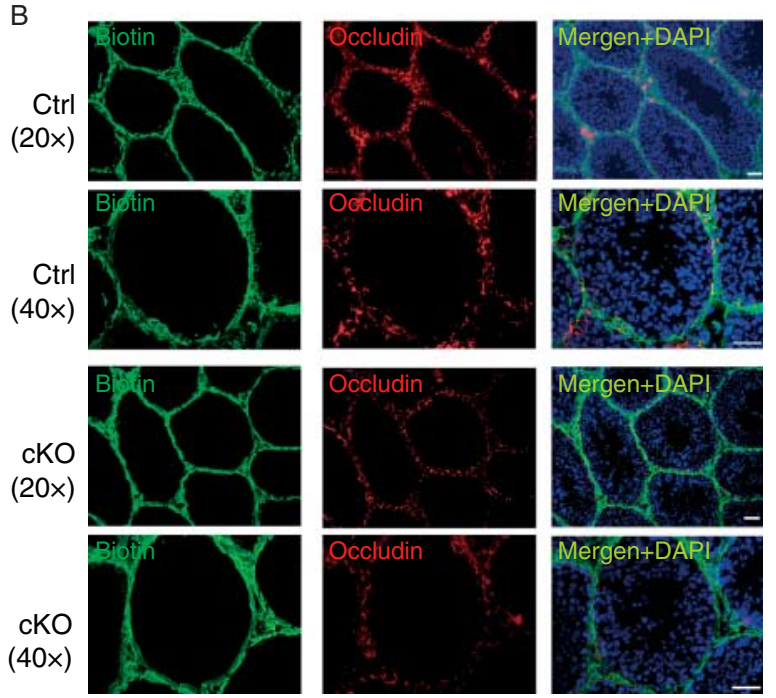

Figure 4 The integrity of BTB is not affected by downregulation of CXADR. Leakage across the BTB was analyzed in P90 mice by two different methods. (A) An intact BTB in both adult tamoxifen-treated cKO mice (F/F;Cre) and littermate controls (Ctrl) (F/F) prevented the penetration of the electron-dense lanthanum tracer beyond the tight junctions (arrows). Scale bars: $2 \mu \mathrm{m}$ and $500 \mathrm{~nm}$. (B) The fluorescent biotin tracer was restricted to the basal compartment of seminiferous tubules $30 \mathrm{~min}$ after injection into the interstitial space in the testes. The tight junctions were stained with an antibody toward occludin. DAPI was used to visualize nuclei. Scale bars: 10 and $40 \mu \mathrm{m}$ (low and high magnifications). At least three mice were used in each experiment.

excised testes in electron-dense lanthanum tracer grains, and by intra-testicular injection of fluorescent biotin tracer. Both of these chemicals are restricted to enter seminiferous tubules if the BTB is intact. When analyzed by TEM, the lanthanum tracer was restricted at the Sertoli cell barrier preventing its passage into the lumen of seminiferous tubular in both cKO animals and littermate controls (Fig. 4A). This phenomenon was common to all the seminiferous tubules irrespective of stages. Similarly, the biotin tracer was not able to pass the BTB and was instead restricted to the interstitial space and the basal compartment in both cKO and control testis when analyzed by immunofluorescence microscopy (Fig. 4B).
The same results were obtained when mice were analyzed at the age of 8 months (length of experiment and data not shown). Immunofluorescence staining using an occludin-specific antibody was used as a marker for tight junctions. These results demonstrate that the integrity and function of the BTB is maintained in the absence of CXADR.

\section{CXADR-negative sperm can fertilize WT eggs}

For the fertility assessment, cKO males and their littermate controls were mated with WT females 6 weeks after the last tamoxifen treatment. The cKO mice gave rise to similar number of pups per litter as the control mice (Fig. 5A). Genotyping of the pups demonstrated that $95 \%$ of the pups showed the presence of a single WT band and the rest of $5 \%$ pups had heterozygous band (Fig. 5B). This data suggests that CXADR-negative sperm could fertilize a WT egg. Interestingly, the genotype of the pups from above mating of CXADR cKO mice showed that $90 \%$ of cKO pups displayed DNA fragments of $211 \mathrm{bp}$ for the WT allele from WT egg and the absence of lox P-flanked allele (261 bp) from CXADR cKO sperm. The F/F controls showed heterozygote bands showing the presence of both lox P-flanked from F/F male mice and WT allele from WT female mice (Fig. 5B).

\section{Barrier formation and function is not affected by depletion of CXADR during the prepubertal period}

Owing to the strong and widespread expression of CXADR during the prepubertal period, CXADR has been claimed to have role in the establishment of the BTB. In order to
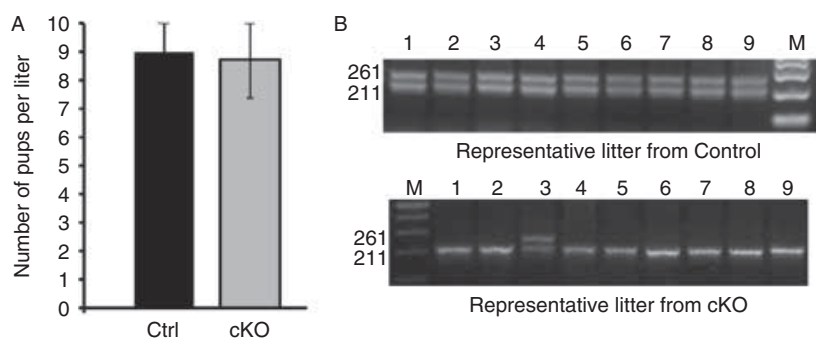

Figure 5 CXADR-negative sperm can fertilize WT eggs. (A) Adult mice at P80, tamoxifen-treated CXADR cKO mice (F/F;Cre) $(n=8)$, and littermate controls (Ctrl) (F/F) $(n=7)$ were mated with WT females $(n=16)$. Mating cages were monitored for a period of 3 months to determine the average number of pups per litter. No significant difference between the two groups was observed ( $P>0.05$; Student's $t$-test; $P$ value $=0.58$ ). The graphs represent the mean number of pups per litter in each group, and error bars indicate the s.D. (B) Pups were genotyped by PCR on tail DNA isolated from pups from representative litters of tamoxifen-treated $\mathrm{CKO}$ mice (F/F;Cre) $(n=5)$ and littermate controls (Ctrl) (F/F) mice $(n=5)$ mated with 6-week-old WT females as described in 'Materials and methods' section. The DNA fragment of 211 bp represents the WT allele whereas the $261 \mathrm{bp}$ fragment represents the lox P-flanked allele. In DNA from cKO animals, in which the two lox $\mathrm{P}$ sites have recombined, this PCR does not give rise to any PCR product. $M$, size marker. 
analyze the role of CXADR in this process, cKO pups were created by injecting tamoxifen at P8, that is before the BTB is formed in mice (Nagano \& Suzuki 1976, Meng et al. 2005). CXADR was efficiently and irreversibly downregulated in the cKO pups 1-2 days after the first tamoxifen treatment as analyzed by PCR analysis. Western blot analysis of testicular extracts from P24, P49, and P90 mice showed CXADR downregulation (Pazirandeh et al. 2011; Fig. 6A and data not shown).

The cKO pups and littermates controls were analyzed for morphology, BTB integrity, and fertility at P49 and adult age. There were no histological differences in the seminiferous tubules in cKO compared with the littermate controls, and all animals displayed a normal repertoire of germ cells in the tubules (Fig. 6B). The BTB was intact as determined by the restricted distribution of biotin tracer outside of the seminiferous tubules (Fig. 6C). Immunofluorescence staining using an occludin-specific antibody was used as a marker for tight junctions. Finally, mating of the cKO mice with WT females resulted in comparable number of pups as compared with their littermate controls (Fig. 6D).

\section{Discussion}

Numerous indirect evidence indicate that the junction protein CXADR has an important role in testis development and physiology. Despite this, in this study, we demonstrate that CXADR is dispensable for normal testis development and function in mice.

Histological analysis of testicular sections from adult CXADR CKO mice revealed no obvious difference in tubular size and a normal distribution of germ cells in all stages of differentiation. Both migration of preleptotene/ leptotene cells across the BTB and germ cell differentiation therefore appear normal in the absence of CXADR. This result was surprising because the finding that CXADR is expressed in a stage-dependent manner in the BTB and also interacts with proteins important for testis function led us to hypothesize a role for CXADR in spermatogenesis (Cohen et al. 2001, Zen et al. 2005, Mirza et al. $2006,2007)$. The results instead imply that the interaction between CXADR and JAML, previously suggested to confer transepithelial migration of cells in other epithelia, appears not to have the same role in the BTB. Similarly, the mechanism by which JAM-C control germ cell differentiation does not appear to involve CXADR, because disruption of the interaction between these two proteins does not affect germ cell differentiation.

Expression of CXADR was previously shown to correlate with epithelial permeability both in vivo and in vitro, and loss of CXADR results in mislocalization of the tight junction proteins occludin and ZO1 at the BTB in Sertoli cells cultured in vitro (Cohen et al. 2001, Raschperger et al. 2006, Su et al. 2012). However, our ultrastructural analysis of the cellular junctions in the testis failed to reveal any differences between CXADR CKO and control mice, and the BTB was intact with no

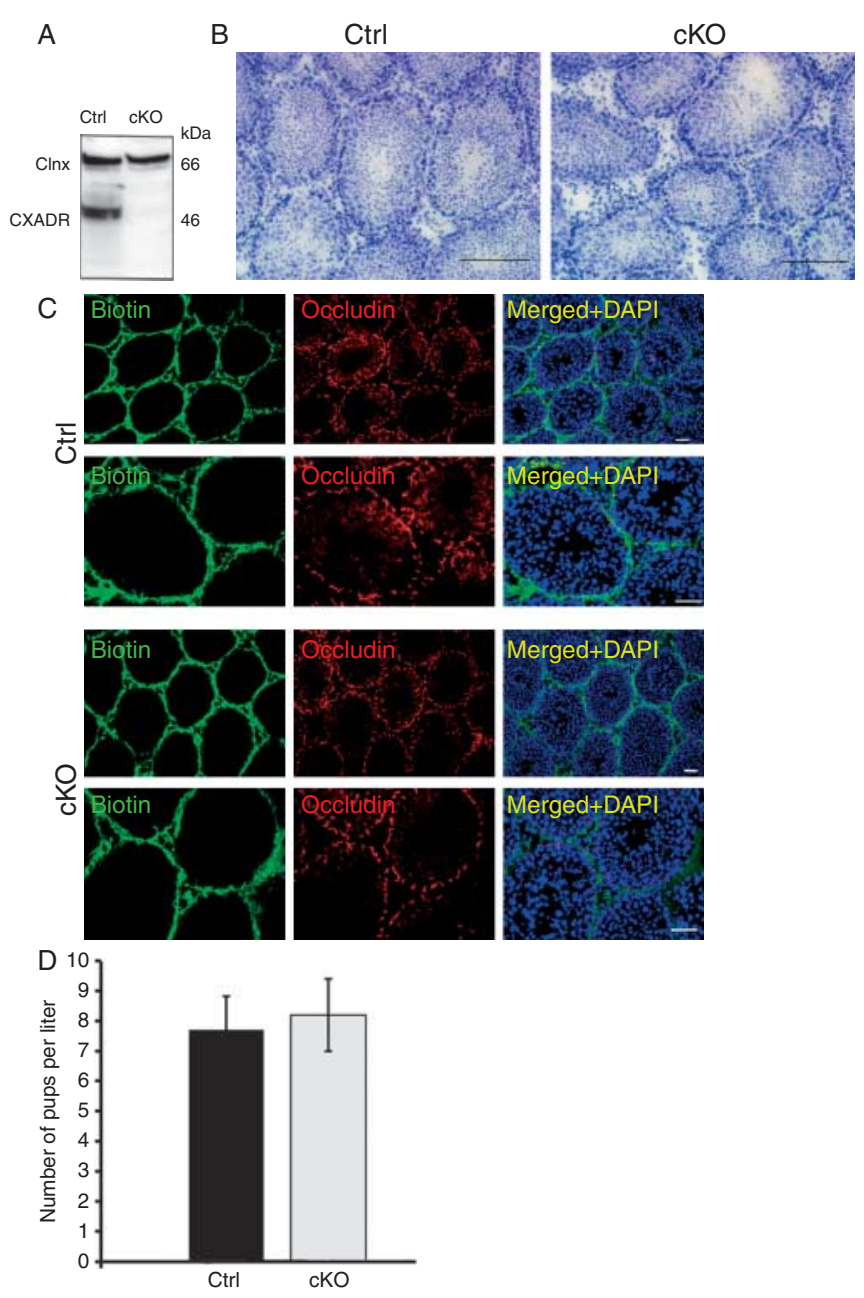

Figure 6 The formation of the BTB and fertility were normal in prepubertal CXADR-depleted mice. CXADR depletion of prepubertal mice at P9 was generated by a single dose of tamoxifen at P8. CKO (F/F;Cre) $(n=7)$ and control (Ctrl) (F/F) littermate $(n=7)$. Mice at P49 were used for CXADR protein expression, morphological analysis, and barrier integrity $(A, B$ and C). (A) Western analysis of testicular extract demonstrated an efficient downregulation of CXADR in CKO mice at P49. Calnexin (Clnx) was used as a loading control. (B) Hemotoxylin staining of testicular sections failed to reveal any difference between the two groups in gross morphology and germ cell differentiation at P49. Images are representative of three independent experiments. Scale bar: $50 \mu \mathrm{m}$. (C) A biotin permeation experiment showed that a well-established BTB barrier restricted the passage of biotin from the interstitium to the adluminal compartment in both groups. An antibody toward occludin was used as a marker for tight junctions, and the nuclei were counterstained with DAPI. Images are representative of three independent experiments. Scale bars: 20 and $40 \mu \mathrm{m}$. (D) A fertility experiment was conducted with prepubertal (P9), tamoxifen-treated cKO mice (F/F;Cre) $(n=5)$, and control littermates (Ctrl) $(n=5)$ at the age of 8 weeks. The two groups of mice were mated with WT C57BL6 females $(n=16)$. Each pair was monitored for 3 months. No statistically significant difference between the number of pups per litter was observed $(P$ value $=0.4)$.

leakage of biotin or lanthanum tracers into the tubular lumen. In addition, analysis of the tight junction proteins ZO1, occludin, JAM-A, and claudin-3 failed to reveal any change in amount or subcellular localization in the 
cKO mice further supporting that the BTB was intact. The reason for the discrepancy is not known but likely reflects the differences between in vitro and in vivo model systems. We conclude that CXADR is dispensable for the integrity and maintenance of the BTB in vivo.

We previously reported the presence of CXADR on the surface of acrosome-reacted spermatozoa, indicating its involvement in events succeeding the acrosome reaction, such as passage through zona pellucida or interaction with the egg plasma membrane (Mirza et al. 2006). Surprisingly, the acrosome structure was intact in the CXADR cKO mice. Furthermore, the absence of CXADR in the sperm did not interfere with fertilization, as CXADR cKO male mice were fertile and able to transfer the deleted Cxadr allele to the offspring. In fact $90 \%$ of the pups in each litter carried the deleted Cxadrallele, which correlated well with the percentage of sperm found to lack CXADR expression.

CXADR is highly expressed in both Sertoli and germ cells during perinatal and postnatal development, followed by a rapid downregulation of both mRNA and protein levels (Mirza et al. 2007). The expression of CXADR therefore coincides with the formation of the BTB which occurs around days 11-15 in rodents (Nagano \& Suzuki 1976). CXADR is also a downstream target of follicle-stimulating hormone (Mirza et al. 2007). These results, together with the reports that CXADR affects the formation and maintenance of functional tight junctions in vitro (Cohen et al. 2001, Su et al. 2012), led us to believe that CXADR might be important for the formation of the BTB in the developing testis. Knockdown of CXADR in postnatal mice, however, failed to reveal any effects on BTB integrity and fertility, and the testis of these cKO mice had normal appearance of differentiating spermatocytes at P24 and P49 according to criteria described by Russell (1990). CXADR therefore appears to be dispensable for testis development and formation of the BTB.

To our knowledge, there are no studies analyzing the effects of tamoxifen on the BTB. However, there are reports indicating that tamoxifen can have both positive and negative effects on spermatogenesis in a context in which tamoxifen was administered immediately before analysis (Carreau \& Hess 2010). In our model, tamoxifen is only delivered during a very limited time period (once a day for 5 consecutive days). This treatment is enough to permanently inactivate the Cxadr gene (this manuscript and Pazirandeh etal. (2011)). Tamoxifen has a half-life of 5-7-day in humans, and probably shorter in mice due to faster metabolism. For these reasons, we feel it highly unlikely that tamoxifen would mask any loss of CXADR function in the mice many months after completing the tamoxifen treatments.

Gene $\mathrm{KO}$ and knockdown of integral tight junction proteins and tight junction-associated proteins have revealed a plethora of functions for these proteins in different epithelial barriers in vivo (Furuse 2009). It is becoming increasingly clear that tight junction proteins not only constitute mechanical barriers but also mediate signaling and regulatory roles, which highlights the complexity of epithelial barriers. Each epithelium is structurally and functionally very different, and the phenotype of a particular gene $\mathrm{KO}$ or knockdown depends on the combination of proteins present in the large protein complex that makes up the different barriers. It is therefore not surprising that CXADR, despite expressed in most epithelial barriers in the body and the devastating effects of CXADR KO and knockdown on epithelial barriers and cellular junctions in other tissues (Lim et al. 2008, Pazirandeh et al. 2011, Mirza et al. 2012), does not seem to have a role in the testis. Redundant functions may operate and proteins compensating for the loss of CXADR might ensure function of this important organ to secure survival of the species.

The present study concludes that CXADR alone is not essential for testis development, spermatogenesis, BTB function, or fertility in mice in vivo.

\section{Declaration of interest}

The authors declare that there is no conflict of interest that could be perceived as prejudicing the impartiality of the research reported.

\section{Funding}

The study was supported by Marie Curie Incoming International fellowship grant (FP7 people's program) (to K Sollerbrant and T Sultana). Swedish Cancer Society (to K Sollerbrant). T Sultana also got support from Sällskapet Barnavård and HKH Kronprinsessan Lovisas förening for barnsjukvård/Stiftelsen Axel Tielmans Minnesfond, Stiftelsen Barnavård; Stiftelsen Samariten; Dagmar Ferb's Fund for Cancer; Karolinska Institutets forskningsstiftelse; Lindhés Advokatbyrå AB. M Hou was supported by grants from the AFA Sjukförsäkringsaktiebolags Jubileumsstiftelse and Stiftelsen Svenska Sällskapet för Medicinsk Forskning (SSMF). The funders had no role in study design, data collection and analysis, decision to publish, or preparation of the manuscript.

\section{Acknowledgements}

The authors thank Emelie Ekwurtzel and Dr Ulrik Kvist for the technical support.

\section{References}

Andersson AM \& Pettersson RF 1998 Targeting of a short peptide derived from the cytoplasmic tail of the G1 membrane glycoprotein of Uukuniemi virus (Bunyaviridae) to the Golgi complex. Journal of Virology 72 9585-9596.

Bjorndahl L, Barratt CL, Fraser LR, Kvist U \& Mortimer D 2002 ESHRE basic semen analysis courses 1995-1999: immediate beneficial effects of standardized training. Human Reproduction 17 1299-1305. (doi:10.1093/ humrep/17.5.1299)

Carreau S \& Hess RA 2010 Oestrogens and spermatogenesis. Philosophical Transactions of the Royal Society of London. Series B, Biological Sciences 365 1517-1535. (doi:10.1098/rstb.2009.0235)

Chavakis T, Keiper T, Matz-Westphal R, Hersemeyer K, Sachs UJ, Nawroth PP, Preissner KT \& Santoso S 2004 The junctional adhesion 
molecule-C promotes neutrophil transendothelial migration in vitro and in vivo. Journal of Biological Chemistry 279 55602-55608. (doi:10.1074/ jbc.M404676200)

Chretien I, Marcuz A, Courtet M, Katevuo K, Vainio O, Heath JK, White SJ \& Du Pasquier L 1998 CTX, a Xenopus thymocyte receptor, defines a molecular family conserved throughout vertebrates. European Journal of Immunology 28 4094-4104. (doi:10.1002/(SICI)1521-4141(199812)28:12<4094::AIDIMMU4094>3.0.CO;2-2)

Cohen CJ, Shieh JT, Pickles RJ, Okegawa T, Hsieh JT \& Bergelson JM 2001 The coxsackievirus and adenovirus receptor is a transmembrane component of the tight junction. PNAS 98 15191-15196. (doi:10.1073/ pnas.261452898)

Cooke VG, Naik MU \& Naik UP 2006 Fibroblast growth factor-2 failed to induce angiogenesis in junctional adhesion molecule-A-deficient mice. Arteriosclerosis, Thrombosis, and Vascular Biology 26 2005-2011. (doi:10.1161/01.ATV.0000234923.79173.99)

Furuse M 2009 Knockout animals and natural mutations as experimental and diagnostic tool for studying tight junction functions in vivo. Biochimica et Biophysica Acta 1788 813-819. (doi:10.1016/j.bbamem.2008.07.017)

Gliki G, Ebnet K, Aurrand-Lions M, Imhof BA \& Adams RH 2004 Spermatid differentiation requires the assembly of a cell polarity complex downstream of junctional adhesion molecule-C. Nature 431 320-324. (doi:10.1038/nature02877)

Gow A, Southwood CM, Li JS, Pariali M, Riordan GP, Brodie SE, Danias J, Bronstein JM, Kachar B \& Lazzarini RA 1999 CNS myelin and Sertoli cell tight junction strands are absent in Osp/claudin-11 null mice. Cell 99 649-659. (doi:10.1016/S0092-8674(00)81553-6)

Guillemot L, Hammar E, Kaister C, Ritz J, Caille D, Jond L, Bauer C, Meda P \& Citi S 2004 Disruption of the cingulin gene does not prevent tight junction formation but alters gene expression. Journal of Cell Science 117 5245-5256. (doi:10.1242/jcs.01399)

Hayashi S \& McMahon AP 2002 Efficient recombination in diverse tissues by a tamoxifen-inducible form of Cre: a tool for temporally regulated gene activation/inactivation in the mouse. Developmental Biology 244 305-318. (doi:10.1006/dbio.2002.0597)

Lim BK, Xiong D, Dorner A, Youn TJ, Yung A, Liu TI, Gu Y, Dalton ND, Wright AT, Evans SM et al. 2008 Coxsackievirus and adenovirus receptor (CAR) mediates atrioventricular-node function and connexin 45 localization in the murine heart. Journal of Clinical Investigation 118 2758-2770. (doi:10.1172/JCl34777)

Meng J, Holdcraft RW, Shima JE, Griswold MD \& Braun RE 2005 Androgens regulate the permeability of the blood-testis barrier. PNAS 102 16696-16700. (doi:10.1073/pnas.0506084102)

Mirza M, Hreinsson J, Strand ML, Hovatta O, Soder O, Philipson L, Pettersson RF \& Sollerbrant K 2006 Coxsackievirus and adenovirus receptor (CAR) is expressed in male germ cells and forms a complex with the differentiation factor JAM-C in mouse testis. Experimental Cell Research 312 817-830. (doi:10.1016/j.yexcr.2005.11.030)

Mirza M, Petersen C, Nordqvist K \& Sollerbrant K 2007 Coxsackievirus and adenovirus receptor is up-regulated in migratory germ cells during passage of the blood-testis barrier. Endocrinology 148 5459-5469. (doi:10.1210/en.2007-0359)

Mirza M, Pang MF, Zaini MA, Haiko P, Tammela T, Alitalo K, Philipson L, Fuxe J \& Sollerbrant K 2012 Essential role of the coxsackie- and adenovirus receptor (CAR) in development of the lymphatic system in mice. PLOS ONE 7 e37523. (doi:10.1371/journal.pone.0037523)

Moog-Lutz C, Cave-Riant F, Guibal FC, Breau MA, Di Gioia Y, Couraud PO, Cayre YE, Bourdoulous S \& Lutz PG 2003 JAML, a novel protein with characteristics of a junctional adhesion molecule, is induced during differentiation of myeloid leukemia cells. Blood 102 3371-3378. (doi:10.1182/blood-2002-11-3462)

Mruk DD \& Cheng CY 2004 Sertoli-Sertoli and Sertoli-germ cell interactions and their significance in germ cell movement in the seminiferous epithelium during spermatogenesis. Endocrine Reviews 25 747-806. (doi:10.1210/er.2003-0022)

Nagano T \& Suzuki F 1976 The postnatal development of the junctional complexes of the mouse Sertoli cells as revealed by freeze-fracture. Anatomical Record 185 403-417. (doi:10.1002/ar.1091850403)

Neaves WB 1973 Permeability of Sertoli cell tight junctions to lanthanum after ligation of ductus deferens and ductuli efferentes. Journal of Cell Biology 59 559-572. (doi:10.1083/jcb.59.3.559)
Pazirandeh A, Sultana T, Mirza M, Rozell B, Hultenby K, Wallis K, Vennstrom B, Davis B, Arner A, Heuchel R et al. 2011 Multiple phenotypes in adult mice following inactivation of the coxsackievirus and adenovirus receptor (Car) gene. PLoS ONE 6 e20203. (doi:10.1371/ journal.pone.0020203)

Raschperger E, Thyberg J, Pettersson S, Philipson L, Fuxe J \& Pettersson RF 2006 The coxsackie- and adenovirus receptor (CAR) is an in vivo marker for epithelial tight junctions, with a potential role in regulating permeability and tissue homeostasis. Experimental Cell Research 312 1566-1580. (doi:10.1016/j.yexcr.2006.01.025)

Russell L 1977 Movement of spermatocytes from the basal to the adluminal compartment of the rat testis. American Journal of Anatomy $\mathbf{1 4 8}$ 313-328. (doi:10.1002/aja.1001480303)

Russell LD, Ettlin R, Sinha Hikim A \& Clegg E 1990 Histological and Histopathological evaluation of the Testis, Clearwater, FI: Cache River Press.

Saitou M, Furuse M, Sasaki H, Schulzke JD, Fromm M, Takano H, Noda T \& Tsukita S 2000 Complex phenotype of mice lacking occludin, a component of tight junction strands. Molecular Biology of the Cell $\mathbf{1 1}$ 4131-4142. (doi:10.1091/mbc.11.12.4131)

Sakaguchi T, Nishimoto M, Miyagi S, Iwama A, Morita Y, Iwamori N, Nakauchi H, Kiyonari H, Muramatsu M \& Okuda A 2006 Putative "stemness" gene jam-B is not required for maintenance of stem cell state in embryonic, neural, or hematopoietic stem cells. Molecular and Cellular Biology 26 6557-6570. (doi:10.1128/MCB.00729-06)

Shao M, Ghosh A, Cooke VG, Naik UP \& Martin-DeLeon PA 2008 JAM-A is present in mammalian spermatozoa where it is essential for normal motility. Developmental Biology 313 246-255. (doi:10.1016/j.ydbio.2007.10.013)

Shaw CA, Holland PC, Sinnreich M, Allen C, Sollerbrant K, Karpati G \& Nalbantoglu J 2004 Isoform-specific expression of the coxsackie and adenovirus receptor (CAR) in neuromuscular junction and cardiac intercalated discs. BMC Cell Biology 5 42. (doi:10.1186/1471-2121-5-42)

Sollerbrant K, Raschperger E, Mirza M, Engstrom U, Philipson L, Ljungdahl PO \& Pettersson RF 2003 The coxsackievirus and adenovirus receptor (CAR) forms a complex with the PDZ domain-containing protein ligand-of-numb protein-X (LNX). Journal of Biological Chemistry 278 7439-7444. (doi:10.1074/jbc.M205927200)

Su L, Mruk DD \& Cheng CY 2012 Regulation of the blood-testis barrier by coxsackievirus and adenovirus receptor (CAR). American Journal of Physiology. Cell Physiology 303 C843-C853. (doi:10.1152/ajpcell.00218. 2012)

Verdino P \& Wilson IA 2011 JAML and CAR: two more players in T-cell activation. Cell Cycle 10 1341-1342. (doi:10.4161/cc.10.9.15294)

Wang CQ \& Cheng CY 2007 A seamless trespass: germ cell migration across the seminiferous epithelium during spermatogenesis. Journal of Cell Biology 178 549-556. (doi:10.1083/jcb.200704061)

Wang CQ, Mruk DD, Lee WM \& Cheng CY 2007 Coxsackie and adenovirus receptor (CAR) is a product of Sertoli and germ cells in rat testes which is localized at the Sertoli-Sertoli and Sertoli-germ cell interface. Experimental Cell Research 313 1373-1392. (doi:10.1016/j.yexcr.2007.01.017)

Willems A, Batlouni SR, Esnal A, Swinnen JV, Saunders PT, Sharpe RM, Franca LR, De Gendt K \& Verhoeven G 2010 Selective ablation of the androgen receptor in mouse Sertoli cells affects Sertoli cell maturation, barrier formation and cytoskeletal development. PLOS ONE 5 e14168. (doi:10.1371/journal.pone.0014168)

World Health Organization, DoRHaR 2010 In WHO Laboratory Manual for the Examination and Processing of Human Semen, 5th edn. Geneva: World Health Organization.

Young P, Qiu L, Wang D, Zhao S, Gross J \& Feng G 2008 Single-neuron labeling with inducible Cre-mediated knockout in transgenic mice. Nature Neuroscience 11 721-728. (doi:10.1038/nn.2118)

Zen K, Liu Y, McCall IC, Wu T, Lee W, Babbin BA, Nusrat A \& Parkos CA 2005 Neutrophil migration across tight junctions is mediated by adhesive interactions between epithelial coxsackie and adenovirus receptor and a junctional adhesion molecule-like protein on neutrophils. Molecular Biology of the Cell 16 2694-2703. (doi:10.1091/mbc.E05-01-0036)

Received 18 December 2013

First decision 27 January 2014

Revised manuscript received 19 February 2014

Accepted 11 March 2014 